\title{
The educational potential of technical university educational space: system-activity aspect
}

\author{
Valentina Kolmakova ${ }^{1, *}$, Denis Shalkov ${ }^{1}$, and Olga Baryshnikova ${ }^{1}$ \\ ${ }^{1}$ Don State Technical University, 344003, Gagarin sq., 1, Rostov on Don, Russia
}

\begin{abstract}
Purposes of the work: 1) to reveal the educational potential of technical university educational space; 2) to consider the transfer mechanisms of cultural and historical experience from the point of view of the system-activity approach. Methodology. The educational potential of a technical university is revealed with the help of the methodological tools of social and psycho-pedagogical disciplines. Results. The article substantiates the need to present new requirements for the formation of an upbringing educational environment in a higher educational institution. The importance of creating favorable psychological and pedagogical conditions in the educational space of the university, influencing the creation of a model of a spiritual and moral personality. Reconstruction of such a model is possible with the interaction of the main psychological and physiological factors: intellectual, emotional-volitional, efficient-practical. Conclusions. Recommendations. The fundamental factor in the development of the emotional sphere of a modern student is upbringing activity of an educational institution, one of the main tasks of which is the formation of a system of continuous spiritual and moral development of the individual. The implementation of the main social functions within the framework of the system-activity approach in teaching and upbringing increases the social responsibility and civic activity of students.
\end{abstract}

\section{Introduction}

The influence of various kinds of transformations in the socio-economic sphere, politics and culture of the 21 st century has changed the composition and space of interaction between the subjects of education, has actualized the revision of traditional ideas about the process of education in a university. Particularly acute today is the question of the spiritual impoverishment of younger generation representatives, the destruction of their emotionalvolitional sphere, the person's ignorance of his action moral essence [1]. This state of affairs predetermines an acute need for the upbringing of a morally stable and spiritually rich personality, preserving national dignity and preserving the cultural and historical heritage.

Education as a specially organized activity provides for the interaction of a teacher and a student in the value-semantic sphere, in which each of them is improved. The result of such upbringing is the student's activity as a form of affirming the subject's value attitudes. The key task on the way to solving this problem is the upbringing of a thinking person with

\footnotetext{
*Corresponding author: vvklm07@mail.ru
} 
a characteristic humanistic culture when creating a spiritual and moral microclimate in a higher educational institution. It is with spiritual and moral education that today they associate the possibility of preserving the moral component of the individual and society as a whole. The spiritually saturated surrounding social environment of the educational space of the university is a fundamental condition for the moral and ethical development of future specialists [2].

The upbringing function in educational activity is manifested in the development of emotional and sensory perception and in the positioning (determination of the strategy of behavior) of the personality at all stages of education [3]. The process of gaining knowledge is accompanied by fostering a sense of active knowledge of the world. In the classroom the search for answers to questions about the meaning of life and the definition of its place in the structure of being is carried out. Such an approach to the content of educational activities contributes to the formation of positive target attitudes and the conscious assimilation of moral and ethical categories.

\section{Methodology}

The educational potential of the educational space of a technical university is revealed using the methodological tools of social and psychological and pedagogical disciplines, in particular, such techniques as observation, description, content analysis, systematization, as well as elements of statistical, distributive and structural-functional analysis methods.

\section{Results}

According to modern pedagogical concepts, the educational process as a transfer of cultural and historical experience is conditioned by three interrelated factors: social-normative, individual-semantic and value-activity.

The implementation of the social and normative aspect in the process of educational activity is achieved through the identification of students with the socio-cultural and professional environment. The use of an individual approach in teaching, taking into account the cognitive capabilities of the student, the peculiarities of his memory, thinking, perception, imagination, taking into account the speed of perception of the educational material and the stock of available knowledge, subsequently determine the choice of the norm of interaction with the environment [4].

The individual-semantic aspect of upbringing in the learning process predetermines the solution of the following pedagogical tasks: the formation of skills in the development by students of their own reasoned opinions and assessments; development of skills of independent critical thinking and analytical listening; developing the ability to work in a group, to debate and carry out constructive criticism of polar points of view; the formation of communication skills; the ability for business and interpersonal interaction in a team; the formation of a personal civic position; the formation of the ability to create and maintain a creative atmosphere in the team.

The value-activity aspect of upbringing is realized in dialogic interaction with the environment. Acquired intellectual metaskills and abilities to generalize, analyze and compare information; independence, consistency, creativity, variability, dialogical, problematic, reflexivity; value orientations of students towards self-realization, selfactualization, self-organization, self-presentation; the ability to generate new non-standard ideas and find alternative ways of solving problems contribute to self-expression, presentation of their personal and professional achievements in educational and future professional activities. 
Research conducted by N.L. Selivanova [5] show that the basis of student education and development is the interaction of intellectual, emotional-volitional, effective-practical aspects. Let us turn to the feature analysis of these factors functioning in their direct interaction in the process of spiritual and moral education.

The cycle of humanitarian disciplines has a significant potential for the development of intellectual abilities in conjunction with the formation of the student's personal qualities and his self-realization. The linguistic situation that took shape at the beginning of the $21 \mathrm{st}$ century (widespread violation of the norms of the literary language, speech aggression, verbal abuse, hesitation, the use of slang and parasitic words, «bureaucratic» (K.I. Chukovsky's term) as a language disease of modern times) has long worried not only philologists, but also the general public [6]. The sociolinguistic phenomena of bullying, mobbing, as well as bossing and trolling as forms of verbal and emotional violence largely destroy the moral and psychological component of the personality and require pedagogical intervention [7].

In the well-known book by M.A. Krongauz «The Russian language on the verge of a nervous breakdown» [8] loosening of the spelling and orthoepic norms, the destruction of the style hierarchy of the usus, total changes in the lexical-grammatical system of the language, the ubiquitous use of words from the so-called «risk group», causing a sharp rejection in the standard, highly educated native speakers. These are, first of all, various kinds of jargon: criminal argot, youth slang, the language of «glamorous» publications, the blogosphere and the «yellow» press, Internet slang, the encrypted language of youth subcultures, etc. At the same time, the author remains on an optimistic position, partly interpreting negative phenomena as signs of the unused creative potential of the language system.

The use of the upbringing teaching methodology in the classroom on the disciplines of the philological cycle not only increases the level of the student's language culture, but also expands the range of spiritual and moral capabilities of students, introduces them to the universal values and values of domestic and world culture. Let us pay attention to the importance of the content side of the didactic material - selected texts reflecting the organic connection and interaction of the concepts «"I" and language», «my language», «language and society». This approach to the linguistic discipline study allows each of the speakers to assess the role of language in their lives. The implementation of communicative competence in this case is achieved through dialogue as a form of educational work and a method of interaction with the outside world and people in the field of education [9]. The use of a text-centered approach to the linguistic material systematization contributes to the solution of lingual-didactic goals.

Classroom work on the study of linguistic heritage provides for the targeting of students to develop their personality in a positive moral way. The activation of students' mental activity in such classes contributes to the development of the skills to put forward their own hypothesis and argue their own position when solving the discovered problem. In the process of subject-subject communication, the intellectual potential of students increases, which in turn contributes to the awareness of civic-patriotic duty.

A special educational resource is possessed by the works of recognized scientists teachers, linguists, philosophers - which can be offered for consideration in classroom lessons (for example, on such educational disciplines as «Business Communication» or «Culture of Oral and Written Speech»). In particular, a fragment of the book «Letters about good and beautiful» by Academician D.S. Likhachev - «Letter twelfth. A person must be intelligent» [10] - actualizes the problem of educating oneself to be intelligent, which will help to maintain both physical and moral health. Among the main issues that traditionally arouse particular interest among students is the formation of worldview goal-orientations: problems of personal growth, a humanistic approach in the learning process, issues of labor 
education, a personality-oriented paradigm in education and upbringing, identification of true values and pseudo-culture of the mass consumption era of.

Parental letters and teachings to children are one of the ancient literary and pedagogical genres that are quite widespread among different peoples of the world and have not lost their relevance to the present time. The key problem of social development is the transfer of life and cultural-historical experience from generation to generation, it is successfully solved in «Letters to the Son» by V.A. Sukhomlinsky: «... always, in all circumstances, to remain human»; «There is only one truth - that which does, brings, does good to people»; «In order to truly know happiness, a person from childhood should find joy in creating happiness for other people, for a team, for society» [11].

For discussion in the student audience, it is advisable to bring the issues of delineating such concepts as «education» and «intelligence», «intelligence» and «good breeding». The work on the essay «The social duty of every person is to be intelligent» and the compilation of a verbal portrait of an intelligent person based on the statements of Likhachev, Sukhomlinsky and other educational thinkers contribute to the formation of vital postulates in students that structure the worldview paradigm.

An increase in the intellectual level in the classroom on business communication, the culture of oral and written speech, language communication in the professional sphere with the use of an effective and practical method is facilitated by the research activities of students of the bachelor's degree and magistracy, dedicated to the study of the state of the modern Russian language [12] and its position in the world community [13].

Such a methodological solution to the content side organization of the lesson broadens the intellectual horizons of the developing personality: it improves intellectual skills and competencies, develops communicative and pragmatic skills, increases the culture of mental work, and updates the rules of speech interaction and etiquette.

The regulator and driving force of the cognitive activity of students, along with the intellectual, is the emotional-volitional factor. The emotional sphere of the student's personality is a system of multidirectional «responses» in the form of feelings. Feelings as a way of expressing stable emotional relationships reflect an individual vision of the surrounding world.

An educational institution plays a significant role in the development of the emotional sphere of a student as a leading link in the system of lifelong education. In the studying process of social and humanitarian orientation disciplines a goal-setting attitude is realized to form students' emotive sensitivity, emotional responsiveness, self-criticism, and the development of sanogenic thinking (managing emotions through reflection). In case of the successful implementation of the set educational goals, students will lay a reliable foundation for a responsible attitude towards the world and people.

According to psychology feelings are a derivative of the whole personality: a person is brought up - feelings are also brought up. Emotional and volitional enrichment of intellectual content is carried out by modeling the cognitive interests of students, the desire of younger generation representatives to study the cultural and historical traditions of their own and other peoples.

The development result of spiritual and moral constructs by the forming personality is the development of an emotional and psychological paradigm of positive feelings, including the joy of life, confidence in the future and in one's own strengths, selfsufficiency; as well as an adequate assessment of the surrounding world from the side of the manifestation of negative emotions or sensually neutral states, such as sadness, grief, calmness or indifference. The intensification of spiritual and moral knowledge is due to the emergence and development of positive feelings in the individual person.

The upbringing space of the Don State Technical University does not only develop patriotism and citizenship as the most important components of the spiritual and moral 
education of student youth, but also generates principles and norms that are at the valuecommunicative and worldview levels [14].

The day of the liberation of Rostov-on-Don from the Nazi invaders on February 14, 1943, held at the DSTU, does not traditionally complete without the participation of prominent political and cultural figures. As part of this event, in the period from 2017 to 2019, the university held meetings with the Soviet and Russian theater and film actor, a master of artistic words, a public figure and teacher V.S. Lanovoy. The attraction of demonstration material and film works with the participation of the actor evokes various emotions in the audience: a sense of involvement in historical events, a sense of community of own destiny with the destinies of the whole nation.

According to the strategic project of DSTU for the comprehensive support of sociocultural initiatives of the Rostov region residents, the educational space of the university is not limited to the framework of an educational institution. On the basis of the university, multifaceted activities are carried out to increase the civic engagement of the population of the Rostov region. The involvement of the region residents in socio-cultural and volunteer activities through interaction with the student youth of DSTU increases the social and civic responsibility of all project participants.

Within the framework of its implementation, classes are carried out by students of DSTU on teaching volunteer and volunteer activities, the target audience of which are students of schools in the city and region. Classes in the «peer-to-peer» format are aimed at increasing the social responsibility and civic activity of schoolchildren and allow them to realize their main social functions (reproductive, innovative, translational), as a result of which young people acquire social maturity, go through the stage becoming as a subject of social relations.

The need to use the system-activity approach in the spiritual and moral education of students is due to the importance of patriotism and civic responsibility formation. The acquired knowledge about people from the immediate environment and the entire ethnosociety is transferred into the persistent beliefs of the individual. The guarantee of the personality formation success is the student awareness of the world role and significance around them in life, the type variety of potential activities. In this regard, it becomes necessary to include students purposefully in various forms of creative and good-natured activity filled with spiritual and moral content: participation in competitions and Olympiads, exhibitions on national culture; conducting conversations, debates and round tables on moral and ethical topics; organization of flash mobs [15], excursions, tourist trips and other cultural events.

An important indicator of the implementation of the activity approach in the spiritual and moral education of DSTU students is the popularization of various types of sports activities among young people. The equestrian club of the DSTU «Horse Run» is the first university equestrian club that began its activities on the Don in 2017. The tasks of the club include not only horse riding training, but also the formation of a humane attitude towards the world around us, the spiritual enrichment of the individual, and the fostering of tolerance.

The competition calendar of the yacht club «Tikhy Don», founded in 2012, includes not only regional student competitions, but also All-Russian and International competitions. The members of this yacht club take an active part in regattas along with professional athletes. Any student or employee of the DSTU can become a member of the yacht club, regardless of the training level.

Since February 21, 2013 «The Don Sky» aeronautical sports club has been operating at DSTU. The goal of the club is to popularize aeronautics, form sports crews, represent DSTU at All-Russian and International competitions and provide interesting, healthy leisure for students and university staff. 


\section{Conclusions/recommendations}

Summarizing the above, we note that the spiritual and moral formation of the student's personality is carried out both in the process of education and in the process of teaching. The knowledge, skills and abilities acquired in the educational process, as well as the acquired competencies, have a significant impact on the formation of a student as a highly moral person. The activation of the spiritual potential of students in various forms of educational activity, individual and group, develops their empathy, a willingness to help others. Self-knowledge, self-expression, self-improvement and personal self-sufficiency are the predicted optimistic results of students' activities with a rationally organized approach to the educational process organization.

The educational potential of the educational space of a technical university contributes to the rethinking of scientific knowledge and their development into beliefs. It becomes obvious that knowledge in conjunction with the worldview harmonizes human relations. Modern researchers note that the training of specialists at DSTU is «focused on current needs and the near future of organizations and enterprises an aimed at a purely practical focus - the implementation of specific operations in business processes using the latest information technologies» [16]. At the same time, in the learning process, students come to the conclusion that a professionally educated highly moral person is becoming more in demand in the era of digitalization.

The result of educational, research and educational work, which was carried out during the 2019-2020 academic year at the social and humanitarian faculty of DSTU, was the determination of the level of social and communicative development of 100 students who participated in the experiment. At the same time, the following indicators were taken into account: intellectual skills and competencies, communicative and pragmatic skills, culture of mental work, the rules of speech interaction, the level of formation of sanogenic thinking. These descriptors were graded on a 5-point scale, and then were summarized and presented as a percentage. The total scores and percentages are shown in Table 1.

Table 1. Assessment of social and communicative development of students of the social and humanitarian faculty of DSTU

\begin{tabular}{|c|c|c|c|c|c|c|}
\hline \multirow{2}{*}{ Descriptors } & \multicolumn{6}{|c|}{ Activities } \\
\cline { 2 - 7 } & \multicolumn{2}{|c|}{ Training } & \multicolumn{2}{c|}{ Researching } & \multicolumn{2}{c|}{ Educational } \\
\cline { 2 - 7 } & $\begin{array}{c}\text { In } \\
\text { points }\end{array}$ & In \% & $\begin{array}{c}\text { In } \\
\text { points }\end{array}$ & In \% & $\begin{array}{c}\text { In } \\
\text { points }\end{array}$ & In \% \\
\hline $\begin{array}{c}\text { Intellectual skills and } \\
\text { competencies }\end{array}$ & 390 & 78 & 241 & 48.2 & 274 & 54.8 \\
\hline $\begin{array}{c}\text { Communication and } \\
\text { pragmatic skills }\end{array}$ & 410 & 82 & 310 & 62 & 324 & 64.8 \\
\hline Mental Work Culture & 357 & 71,4 & 325 & 65 & 370 & 74 \\
\hline Speech interaction rules & 415 & 83 & 290 & 58 & 426 & 85.2 \\
\hline Sanogenic thinking & 348 & 69.6 & 353 & 70.6 & 412 & 82.4 \\
\hline
\end{tabular}

Interpretation of the presented results allows us to assert that the educational activity of students plays a special role in the formation of social and communicative descriptors. However, other types of activity, educational and research, are also of great importance in this process, which contribute to a more intensive assimilation of intellectual and communicative-pragmatic meta-skills, the rules of speech interaction and the laws of sanogenic thinking.

The intellectual readiness of modern youth for spiritual enrichment and growth, the desire to satisfy individual spiritual and moral needs predetermine the moral choice of the student. The undoubted spiritual wealth of the emerging young person is the morally conditioned orientation of ideological motives, the desire for self-improvement, cognitive 
interests, persistent moral convictions and views, spiritual and moral guidelines. The most important task of the educational process in a modern higher educational institution is to create a favorable psychological and pedagogical microclimate that contributes to the formation of a reference spiritual and moral personality.

\section{References}

1. L. E. Schmidt, Restless Souls: The Making of American Spirituality, University of California Press (2012)

2. V. V. Kolmakova, Determination of the level of formation of an active civic position of a modern student, Philological sciences. Questions of theory and practice, 10-3(64), 182-186 (2016)

3. L. K. Fortova, A. M. Yudina, N. I. Evsyukova, On the development of spirituality in the modern realities of Russian society, in Samara Scientific Bulletin, 9, 1(30), 289293 (2020)

4. P. Kurtz, Multisecularism. A New Agenda, New Jersey, Transaction Publishers (2010)

5. N. L. Selivanova, Theory and practice of education: development and implementation of priority ideas, in New in psychological and pedagogical research, 3(23), 152-163 (2011)

6. V. V. Kolmakova, D. Yu. Shalkov, Features of Russian communicative behavior at the beginning of the XXI century, in Bulletin of the Pyatigorsk State University, 4, 61-64 (2018)

7. V. V. Kolmakova, D. Yu. Shalkov, Linguistic aspects of bullying and mobbing in modern communication, in Higher education teacher in the XXI century: proceedings of the 16th International Scientific and Practical Conference, Rostov-on-Don, RSTU, 16, 122-130 (2019)

8. M. A. Krongauz, Russian language on the verge of a nervous breakdown (Moscow, AST, CORPUS, 2018)

9. Ya. S. Kosyakova, The role of dialogue learning in the process of realizing competencies in the framework of teaching the discipline «Business communication» at the university, in Education and pedagogy: topical issues: monograph (Cheboksary, Publishing House «Sreda», 2020)

10. D. S. Likhachev, Letter twelfth. A person must be intelligent, in Small collected works, 439-442 (St. Petersburg, Azbuka, Azbuka-Atticus, 2018)

11. V. A. Sukhomlinsky, Letters to my son (2018) available at: https://azbyka.ru/deti/pisma-k-sy-nu-suhomlinskij-v-a (Last accessed 07.24.2020)

12. V. V. Kolmakova, M. S. Zvezdin, Features of the urbanonims of the Northern residential area and the Myasnikovan microdistrict of the Voroshilovsky district of Rostov-on-Don, in Young researcher of the Don, 4(19), 135-140 (2019)

13. D. A. Korotych, V. V. Kolmakova, The position of the Russian language in the Baltic States, in Problems and prospects of development of Russia: Youth look into the future: collection of articles. scientific. Art. All-Russian scientific conference, In 4 volumes, 237-240 (2018)

14. O. E. Baryshnikova, L. A. Pudeyan, The main directions and conditions for increasing the effectiveness of the system of military-patriotic education, in Victory May 1945: collection of articles. Art., Ministry of Education and Science of the Russian Federation, DSTU, Trade Union of Public Education and Science Workers of the 
Russian Federation, Primary Trade Union Organization of DSTU Workers, Primary Trade Union Organization of Students of DSTU, 22-24 (2017)

15. V. V. Kolmakova, D. Yu. Shalkov, Literary flash mob as an interactive form of philological education, in Higher education teacher in the XXI century: proceedings of the 17th International Scientific and Practical Conference, Rostov-on-Don, RGUPS, 17, 231-237 (2020)

16. S. V. Bylkova, E. P. Chubova, Features of the professional training of document managers and archivists at the present stage: the experience of a technical university, in Information technologies and systems in the field of document management and archival science: materials of the VIII International Scientific and Practical Conference, 102-107 (2019) 